\title{
CONTRIBUIÇÕES DE PRÁTICAS COLABORATIVAS NO DESENVOLVIMENTO LINGUÍSTICO E CULTURAL DE CRIANÇAS SURDAS POR MEIO DA LITERATURA INFANTIL*
}

\author{
Érica Aparecida Garrutti de Lourenço \\ Larissa Daniele de Jesus Coelho
}

\section{Introdução}

Chega mais perto e contempla as palavras.

Cada uma

tem mil faces secretas sob a face neutra e te pergunta, sem interesse pela resposta, pobre ou terrivel, que the deres:

Trouxeste a chave?

Carlos Drummond de Andrade

Carlos Drummond de Andrade, em "Procura da Poesia", cujo trecho foi mencionado acima, faz-nos um convite irrecusável: chegar mais perto das palavras e contemplá-las. Como um aceite a esse convite, temos, neste capítulo, o propósito de refletir sobre contribuições de práticas educativas envolvendo a literatura infantil na educação de crianças surdas. Nossa chave, tal como argumentado no poema de Drummond, compõe-se do estreito relacionamento entre o significado da palavra como linguagem, especialmente a partir dos estudos de Vygotsky $(2007$; 2008), e o significado da palavra como poética infantil, comumente expressa em contos e narrativas infantis (ABRAMOVICH, 1991; RIZZOLI, 2005).

Para que a criança se constitua na e pela palavra/linguagem, e por outras funç̃ões psicológicas superiores, a mediação do(s) outro(s) é uma necessidade contínua. Nessa perspectiva, Vygotsky $(2008$, p. 63) destaca que, desde a evolução da fala e do pensamento em crianças pequenas para a fala interior e o pensamento verbal em crianças maiores, "a natureza do próprio

*DOI - 10.29388/978-65-86678-60-4-0-f.155-174 
desenvolvimento se transforma, do biológico para o sociohistórico". O homem se define nas situações de trocas e na sua organização cognitiva pelo uso de sistemas simbólicos. Dentre eles, a linguagem exerce papel de destaque.

Em situações de interlocução, de participação em práticas discursivas, as crianças vão se apropriando dos conhecimentos de mundo e descobrindo formas de se posicionar em relação ao(s) outro(s) nos diferentes tempos e espaços que integram. Como o sujeito se relaciona com o mundo e como se vê representado nessas relações são algumas das questões-chave nesse continuum; ele significa o mundo e ao mesmo tempo significa a si próprio.

Pesquisas atuais, também fundamentadas numa compreensão histórico-cultural do sujeito surdo (TARTUCl, 2015; GURGEL et al., 2016; ANDREIS-WITKOSKI; FILIETAZ, 2019), revelam contribuições da organização de espaços educativos que, desde a educação infantil, sejam bilíngues; espaços nos quais a língua de sinais - Língua Brasileira de Sinais (Libras) - seja a língua da mediação pedagógica e das trocas entre pares coetâneos.

A criança surda imersa nesses espaços encontra na Libras uma língua para se comunicar, internalizar e produzir significados, lembrar-se de acontecimentos, imaginar e criar narrativas e posicionar-se culturalmente, de modo a ir se constituindo como "ser surdo" (LOPES; VEIGA-NETO, 2010, p. $116)^{1}$.

Considerando que grande parte das crianças surdas brasileiras têm contato com sua língua de conforto ${ }^{2}$ somente a partir de seu ingresso nos espaços educativos, sendo privada, portanto, do acesso a uma língua de trocas comunicativas em seus lares, a socioconstrução da linguagem nessas crianças já foi prejudicada. Diante disso, eleva-se a necessidade da organização de espaços bilíngues, desde a educação infantil, para que os pequenos encontrem

\footnotetext{
${ }^{1}$ Conforme Lopes e Veiga-Neto (2010, p. 116), a expressão "ser surdo" abrange uma experiência de ser e de estar no mundo, que é vivida no coletivo e sentida de maneiras particulares. Além disso, os autores pontuam que, "além da língua de sinais, da arte, do teatro e da poesia surda, a noção de luta, a necessidade de viver em grupo e a experiência do olhar são marcadores que nos permitem falar de identidades surdas fundadas em uma alteridade e uma forma de ser surdo". ${ }^{2} \mathrm{O}$ conforto linguístico requer a organização de espaços de interlocução constituídos pelo uso de uma língua que seja plenamente acessível aos sujeitos, que considere suas diferenças identitárias e culturais. Conforme Santiago (2013, p. 147), entende-se por conforto linguístico "a situação de uma pessoa que se comunica e interage com o mundo, por meio de uma língua que Ihe é natural, língua esta que lhe dá condições de entender e interpretar o mundo de maneira completa e significativa, e de produzir sentido nos enunciados nesta língua".
} 
na Libras o principal sistema simbólico das relações múltiplas que se estabelecerão nas díades criança(s)-criança(s) e criança(s)-adulto(s).

De acordo com Santana e Bergamo (2005, p. 570), a língua de sinais é "passaporte de entrada para o universo social" de pessoas surdas. De posse desse passaporte, compreensões diversas poderão ser construídas na multiplicidade de práticas e interações sociais. Em relação às crianças surdas e ao universo social da escola, esse passaporte encontra na literatura infantil um importante espaço de experimentação de práticas discursivas.

A literatura infantil é um fenômeno de linguagem e uma experiência vital e cultural (COELHO, 1993), pois as histórias infantis permitem que as crianças encontrem diversas possibilidades de exploração e construção de seu conhecimento de mundo.

Por meio do universo da literatura infantil, a criança pode ter acesso a informações sobre como a sociedade se organiza no tempo e nos espaços, bem como viajar por territórios conhecidos e outros a serem desvendados.

Contar e ouvir uma história é terreno em que se pode "brotar a imaginação e abrir caminhos criativos" (RIZZOLI, 2005, p. 9). As histórias podem apresentar importantes pistas sobre o mundo e despertar a empatia, além de tantos outros sentimentos que respondam às necessidades mais íntimas de cada um; elas são um modo de

[...] interpretar aquilo que acontece conosco, de encontrar um significado para aquilo que nós fazemos e de dar sentido não apenas a um evento isolado, mas a uma série deles - a várias categorias de eventos. É, por isso, um princípio de estruturação dos processos e das experiências de vida (RIZZOLI, 2005, p. 11, grifo nosso).

A literatura infantil é um campo de experimentação do mundo. Nele, a criança, ao ler, contar ou ouvir uma história, lida com situações ou acontecimentos que apresentam, de maneira sistemática, as relações na sociedade, numa viagem que represente um misto de realidade e ficção, como continuidade ao exercício de linguagem e pensamento.

Considerando as contribuições da literatura infantil no trabalho pedagógico com crianças, aqui se analisa a experiência de uma sequência didática que aconteceu em uma turma multisseriada de alunos surdos, com idade variando de 4 a 8 anos, de uma escola municipal, sob condução de uma de suas professoras, também autora deste texto. A experiência teve início com 
a visita de crianças surdas a uma universidade - como um convite proposto por uma professora-pesquisadora, uma das autoras desta escrita - e teve continuidade no ambiente escolar. A sequência de atividades foi finalizada com apresentação de uma peça teatral em um evento promovido pela escola e em outro pela secretaria de educação municipal. A prática pedagógica proposta tinha como objetivo que as crianças, a partir de uma vivência com diferentes versões de um conto infantil clássico, realizassem recontos e criassem uma releitura que trouxesse particularidades da turma.

\section{O desenvolvimento da criança surda por meio de práticas educativas com literatura infantil}

O uso social dos sistemas simbólicos, dentre os quais a Libras, como linguagem, exerce papel central no desenvolvimento do sujeito surdo, é o que permitirá a representação da realidade e o domínio do aspecto cultural. Com isso, nota-se que a apropriação do conhecimento humano passa, então, pela capacidade de emprego dos signos e instrumentos em situações compartilhadas socialmente.

De acordo com Vygotsky (2007), a linguagem assume uma função comunicativa e permite que o sujeito planeje a solução de um problema antes de executar uma ação. A fala é tão importante quanto a ação para atingir um objetivo; ambas fazem parte de uma mesma função psicológica complexa, dirigida para a solução do problema. "Quanto mais complexa a ação exigida pela situação e menos direta a solução, maior a importância que a fala adquire na operação como um todo" (VYGOTSKY, 2007, p. 13). A fala se apresenta, em sua função organizadora das ações, como pensamento verbal.

Desse modo, é importante que as práticas educativas na escola permitam às crianças surdas interagir por meio da Libras e organizar suas ações centrando-se na resolução de questões que as desafiam.

Contemplar os interesses e as necessidades das crianças é outro importante ponto no planejamento do trabalho pedagógico e, nesse quesito, a liberdade de criação e a imaginação podem marcar forte presença no cotidiano da escola.

"A ação numa situação imaginária ensina a criança a dirigir seu comportamento não somente pela percepção imediata dos objetos ou pela situação que o afeta de imediato, mas também pelo significado dessa ação" 
(VYGOTSKY, 2007, p. 114). Atividades ainda não possíveis de serem executadas no plano real e desejadas podem ser experimentadas, por exemplo, no brincar de faz de conta ou em uma contação de histórias. Há, então, uma vivência de práticas culturais.

É importante também que as práticas educativas considerem como o sujeito se vê representado nas relações, e como ele constrói sua subjetividade nas práticas discursivas. O reconhecimento de si mesmo acontece num processo semiótico, que pressupõe a relação com o outro. A criança surda, que tem a Libras incorporada na interlocução cotidiana com pares coetâneos e adultos, ouvintes e surdos, encontra maiores possibilidades de expansão das relações interpessoais, que constituem sua organização cognitiva e afetiva e dão sustentação a construção da subjetividade (GOES, 2002), estando intimamente relacionadas às condições concretas de vida.

Em se tratando dos aspectos linguagem, pensamento, imaginação e construção da subjetividade da criança surda, como ser participante da cultura, a literatura infantil pode ser o grande elo quando o objetivo é potencializar tais funções nas atividades em sala de aula. O trabalho com literatura infantil possibilita que as crianças possam se reconhecer, imaginar, interagir, observar, confrontar o ouvido e o visto com o vivido, compreender a realidade e representá-la, associar a realidade e a representação (RIZZOLI, 2005).

Conforme Vieira (2008), o trabalho com literatura infantil permite que a criança percorra, pela linguagem, mundos desconhecidos, crie e recrie realidades, experiencie situações, amplie o conhecimento de mundo, encontre equilíbrio emocional e psíquico, e desenvolva seu senso crítico. Nesse processo, dá-se início à aprendizagem do ser leitor, que, nas palavras de Abramovich (1991, p. 16), significa trilhar um "caminho infinito de descoberta e de compreensão de mundo".

Dada a importância de práticas sociais para uso da linguagem no desenvolvimento dos sujeitos e a restrição de vivências de relações múltiplas na língua de sinais por crianças surdas, nota-se um crescente número de estudos que tecem reflexões sobre contribuições do trabalho com literatura infantil e/ou de contações de histórias e respectiva organização de práticas na educação de crianças surdas (LEBEDEFF et al., 2004/2005; LODI; LUCIANO, 2014; DELMAR, 2016).

Em um estudo pedagógico realizado por Lodi e Luciano (2014), as rodas de conversa que sucederam a contações de histórias revelaram que as 
crianças puderam aprender sobre as particularidades da Libras, vivenciar trocas de papéis e fazer relações com situações cotidianas. Corroborando com essa constatação, Lebedeff et al. (2004; 2005) destacam que as histórias podem ajudar as crianças a realizar inferências e produzir narrativas em sua primeira língua, habilidades basilares também para compreensão dos textos escritos em sua segunda língua (o português). Delmar (2016), por sua vez, apresenta possibilidades de ações pedagógicas de conto e reconto, organizadas a partir da escolha de uma obra infantil, e que destacam o uso de estratégias e recursos com pistas predominantemente visuais, atividades priorizadas neste relato de experiência.

\section{O início da experiência: encenações de histórias infantis na universidade}

Por dois anos seguidos, os licenciandos matriculados em uma disciplina com ementa focada na educação bilíngue para alunos surdos que compõe a grade curricular do curso de Pedagogia em uma universidade pública prepararam e apresentaram dois momentos de encenações em Libras de clássicos da literatura infantil, sendo um por ano. No âmbito dessa disciplina, a literatura infantil foi tomada como campo de estudo lexical e gramatical da Libras por parte dos estudantes que iniciavam o percurso de aprendizagem dessa língua.

As encenações dos pedagogos em formação tiveram como plateia crianças surdas que integravam duas turmas bilíngues de uma escola regular da secretaria de educação de um município da região metropolitana de São Paulo. Tais turmas têm a Libras como língua do ensino e a língua portuguesa em sua modalidade escrita como segunda língua.

Os alunos surdos contavam com a Libras como língua de mediação pedagógica, e somente a usavam no âmbito escolar, haja vista que seus familiares não se comunicavam com eles na língua de sinais. Cada uma das turmas era dirigida por duas professoras fluentes em Libras que atuavam em regime de docência compartilhada.

Em ambas as visitas à universidade, as crianças, além de assistirem às encenações, participaram de atividades lúdicas complementares como, por exemplo, de exploração da biblioteca e da brinquedoteca, organizadas e 
mediadas pelos adultos presentes - professoras, monitoras, bolsistas e educadores surdos visitantes.

$\mathrm{Na}$ primeira visita à universidade, as encenações dos licenciandos contemplaram releituras de textos literários inspirados no clássico "João e Maria" e, na segunda - material de análise da experiência aqui relatada - em versões do clássico "Os Três Porquinhos".

Os livros de literatura infantil que inspiraram as encenações da segunda visita adicionavam detalhes curiosos ao clássico de Joseph Jacobs: as casas ou os porquinhos assumiam formas geométricas (TORERO, PIMENTA, 2017; VILLELA, 2006), os protagonistas eram jacarés construtores de casas em lugares inusitados (KETTEMAN, 2010); os protagonistas eram lobinhos, e o porco era o vilão (TRIVIZAS, 1996), e o lobo derrubava as casas acidentalmente, pois ele queria somente uma xícara de açúcar para preparar um bolo (SCIESZKA, 1993).

O planejamento da visita pelos alunos do curso de Pedagogia, atividade de finalização da disciplina, contemplou ações que duraram dois meses consecutivos e teve o seguinte público: turmas de educação bilíngue formadas por crianças surdas. Para tanto, foram necessários muito estudo e pesquisas por parte dos licenciandos. Afinal, o objetivo da atividade era proporcionar narrativas e situações de trocas em Libras, considerando o perfil das crianças.

A fim de preparar as crianças para a segunda visita à universidade, as professoras da escola realizaram rodas de conversa para explicar qual seria a sequência de atividades e para falar da importância de todos participarem delas.

Considerando que a visita anterior tinha proporcionado momentos de muita interação entre as crianças e os adultos, com os estudantes do curso de Pedagogia principalmente, a expectativa para a segunda visita era grande. Esses momentos eram importantes para as crianças, visto que elas não contavam, em seu convívio social, com pessoas que partilhassem de uma língua comum, limitando sua interação até mesmo com pessoas próximas.

Isto posto, as crianças já sabiam que elas seriam protagonistas nas atividades que aconteceriam na universidade, e que todas as pessoas ali presentes partilhavam o desejo da interação, o que ampliaria o raio social do qual fazem parte e que, devido às circunstâncias anteriormente citadas, é tão limitado. 
Durante as encenações das histórias da segunda visita, que foram cinco no total, as crianças observavam atentamente cada apresentação. A semelhança dos enredos com uma história já conhecida, "Os Três Porquinhos", levou-as a esperar com ansiedade o desenrolar de cada releitura. Em alguns momentos, as crianças até tentavam direcionar as ações dos personagens, e a expectativa para cada nova encenação era grande e vinha acompanhada de curiosidades do tipo: Quais serão os personagens? Como eles serão? Quais recursos e acessórios estarão presentes na história?

Esse interesse permitia que as crianças adentrassem em cada nova história, e um dos pontos centrais a despertá-lo foi o planejamento de recursos visuais pelos licenciandos. Cada personagem utilizava acessórios que facilitavam a sua identificação e os recursos complementares como, por exemplo, para a construção das casas dos porquinhos, tornavam o processo mais claro.

Refletindo sobre a importância da leitura de informações visuais, como as imagens, no trabalho do professor, Reily (2012) destaca as imagens como recurso cultural presente na história da humanidade e, portanto, como um importante material pedagógico no currículo escolar. O planejamento dos recursos visuais nas releituras fez-se presente na caracterização dos personagens, no uso dos acessórios e na utilização dos espaços, a fim de que as informações do roteiro fossem compreendidas no uso articulado da linguagem verbal e não verbal. Desse modo, possibilitou-se o acesso por parte das crianças a informações e características importantes para o entendimento dos enredos.

A visita propiciou, aos alunos surdos, encantamento e aprendizagens tão significativas, que as professoras envolvidas no projeto optaram por explorar a temática na escola. Por parte de uma das turmas, na experiência que relatamos aqui, a motivação por uma das versões encenadas foi tão grande, que permitiu às professoras ampliar as experiências em sala de aula para as diferentes áreas do conhecimento, resultando em um plano de atividades interdisciplinares, com elementos do universo da turma para a construção de uma narrativa infantil. 


\section{Continuidade da experiência na escola: recontos e criação de conto próprio}

A sequência didática que envolveu releituras de "Os Três Porquinhos" na escola e conduzida pelas professoras contemplou as seguintes atividades: roda de conversa posterior à visita na universidade, recontos das releituras assistidas na universidade, criação de uma releitura da turma (definição de personagens e roteiro), produção de vídeos de registro em Libras, produção de um livro de registro da história em português e ensaios para posterior apresentação teatral da narrativa em um evento da escola e em outro promovido pela secretaria de educação do município.

Após a visita, por meio de roda de conversa na escola, foram retomadas as atividades realizadas na universidade e as considerações das crianças sobre cada uma delas, o que permitiu que os alunos apontassem como se sentiram e o que lhes chamou mais atenção. Animados e ansiosos para expressarem suas opiniões, eles foram logo dizendo o que mais gostaram nas dramatizações.

Espontaneamente, a turma recontou as histórias dramatizadas, sendo esta a alternativa habitual utilizada para explicar determinados fatos com detalhes. Na versão em que os porquinhos eram os protagonistas, as crianças incorporavam as características e ações do lobo quando assoprava fortemente para derrubar as casas e depois entrava em uma delas pela chaminé. De modo semelhante, na versão em que os jacarezinhos eram os protagonistas, as crianças incorporavam as ações do "javali bundudo" que derrubava as casinhas fazendo movimentos engraçados (KETTEMAN, 2010). Os aspectos que chamavam a atenção da turma eram imitados para trazer aos seus recontos o lado cômico que elas tanto apreciavam.

Em sala de aula, após a leitura de livros de literatura, ou depois de assistir a vídeos de histórias, era comum que as crianças realizassem recontos. Essa estratégia ajudou os alunos a se comunicarem, interagirem e discutirem sobre os acontecimentos narrados sobre a visita. Em meio a diálogos e recontos, as crianças iam percebendo o que era necessário para que fossem compreendidos, e as professoras encontravam pistas para avaliar seus entendimentos sobre o que Ihes foi passado e traçar planos para avançar na construção de narrativas. 
O reconto implica em compreender o que foi narrado e recompô-lo na sequência de acontecimentos. Atrelada à percepção de quem ouve ou lê uma história, e se prepara para o reconto, há uma organização cognitiva que forma "outra trama", "outra malha textual", podendo ser semelhante ou não ao texto base (SOUZA; COSTA; SAMPAIO, 2016, p. 555).

Os alunos envolvidos nos recontos, e com a mediação das professoras, puderam dar novas formas à malha textual (re)estruturada coletivamente pela turma. Eles autonomamente se organizaram, determinando o que cada um deles faria, os elementos que serviriam para ilustrar os objetos e as características dos personagens, assim como os espaços utilizados. Cada um pode trazer um pouco de si nesse processo.

A observação das professoras da escola revelou que as crianças estavam trazendo diversas expressões não manuais inspiradas na história "Os Três Porquinhos", que já era conhecida por elas devido a leituras realizadas em sala de aula. Além disso, como as casas dos porquinhos, em uma das dramatizações assistidas na universidade, assumiam formas geométricas, tal detalhe foi inserido em seus recontos.

As formas geométricas das casas da história chamaram a atenção das crianças; pois, em sala de aula, estavam sendo realizadas atividades sobre esse assunto. Sendo assim, elas tiveram a oportunidade de observar algo que tinham aprendido, sendo explorado de outra maneira, em uma prática com a qual se identificavam; no caso: o reconto e a dramatização.

Partindo dessa aprendizagem, deu-se início ao processo de construção de uma narrativa que fosse criada pelos alunos e que seria apresentada na escola e em um evento municipal. A narrativa da turma já se distinguia na composição do número de porquinhos protagonistas; em vez de ser composta por três porquinhos, contou com quatro porquinhos, visto que todos consideraram importante representar as seguintes formas geométricas: círculo, triângulo, retângulo e quadrado. Vemos, nesse exemplo, os saberes das crianças sendo incorporados no texto literário, o que evidencia que imaginação e conhecimento podem ocupar o mesmo espaço.

Dentre os recursos e acessórios construídos pelos licenciandos do curso de Pedagogia e doados para a turma, havia as casinhas dos geométricos porquinhos, que foram utilizadas em todos os recontos espontâneos na escola. 
$\mathrm{Na}$ construção da narrativa da turma, as professoras pontuaram algumas questões para possibilitar que toda a turma atuasse na dramatização, visto que nos momentos de recontos os alunos se revezavam entre os personagens para que todos participassem e experienciassem os diferentes pontos de vista. Dentre as questões, as crianças foram desafiadas a pensar em como todas poderiam participar da apresentação.

Inicialmente, a turma decidiu quais crianças fariam os papéis dos quatro porquinhos e do lobo por meio de uma roda de conversa, na qual as personalidades e os interesses de cada aluno foi critério determinante para as escolhas. Assim, dois meninos e duas meninas foram escolhidos pelos alunos para representar esses personagens, conforme critérios descritos a seguir.

O porquinho que construiu a casa mais forte, com a forma quadrada, foi representado pelo aluno considerado mais sério pela turma. Para o porquinho da casa mais frágil, representando a forma triangular, o aluno mais desinibido e brincalhão se propôs a encená-lo. Duas meninas demonstraram o interesse para interpretar os demais porquinhos. Uma delas trouxe vaidade e meiguice para sua personagem, que se preocupava somente em deixar bonita sua casa em formato de círculo. A outra aluna fez o papel do porquinho que construiu a casa com a forma de retângulo e que não conseguiu finalizar a construção por ter se distraído no processo. O papel do lobo foi atribuído à criança que, nos recontos, realizava expressões faciais e corporais desse personagem mais detalhadas. Essas características foram definidas coletivamente durante a construção do roteiro que detalhava as cenas e as falas dos personagens.

Tendo sido atribuídos os personagens principais da história, ainda era preciso criar mais três personagens para que todas as crianças da turma tivessem papéis na narrativa. Aproveitando a espontaneidade das crianças em um momento de reconto, surgiu a ideia de explicar na história que o lobo havia precisado buscar alimento porque sua filha, a bebê loba, estaria com fome. Assim, a necessidade de alimentar a filha foi o que mobilizou o lobo na caça aos porquinhos. A escolha de quem faria essa personagem levou em conta a idade das crianças, seguindo a lógica de que a filha precisaria ser "menor" que seu pai. Dessa forma, uma das crianças menores, que havia sido matriculada recentemente na turma, foi escolhida para ser a bebê loba. 
Como ainda faltava definir papéis para duas crianças, outras versões de "Os Três Porquinhos" foram lidas, a fim de buscar ideias que ajudassem a resolver a questão. Em uma delas, a história era iniciada com a mãe dos porquinhos dando-lhes dinheiro para construir suas casas. Essa história chamou a atenção das crianças, que logo decidiram inserir essa personagem na apresentação. Assim, surgiu a mamãe porquinho, que foi atribuída a uma das alunas maiores. Para a criança sem personagem e recém-chegada à turma, ficou definido que ela seria um bebê porquinho, também seguindo a idade como critério.

As crianças, ao serem levadas a pensar nos sujeitos que comporiam o enredo, foram incitadas a buscar personagens alternativos, além daqueles que elas já conheciam do clássico "Os Três Porquinhos". O objetivo desse exercício era atribuir papéis para todos que integravam a turma. Com esse propósito em mente, os alunos foram levados a conversar e a pensar sobre o assunto e, juntos, encontrar respostas para a situação que as desafiavam.

Tal como destaca Vygotsky (2007), práticas desse tipo favorecem o desenvolvimento das crianças. Na situação relatada, foi preciso mobilizar o uso de signos e instrumentos que permitissem encontrar uma resposta para a questão-chave: como incluir todos os colegas da turma em um enredo que fosse inspirado em um clássico conhecido por eles e em outras releituras? Diante dessa questão, os alunos puderam por meio da fala organizar a construção de uma narrativa da turma. $O$ acesso a releituras na universidade e na escola e a mediação das professoras da turma foram determinantes na criação da nova narrativa. Nesse processo, vemos notadamente as contribuições do trabalho com narrativas infantis para o exercício do pensamento, da linguagem e da imaginação.

A introdução da mamãe porquinho na história recebe destaque no processo inventivo das crianças. Durante a encenação, elementos cômicos foram inseridos na atuação da personagem, quando todas sugeriam detalhes que pareciam incorporar parte da personalidade e das ações de suas mães, quando são por elas repreendidas em seus cotidianos por exemplo.

Ressaltando o potencial das narrativas, Souza, Costa e Sampaio (2016, p. 555) esclarecem que na ação de (re)contar, "o sujeito move as estruturas textuais e tece uma nova trama, um novo tecido que poderá trazer em si as marcas do leitor". Nessa nova trama, desenha-se um modo de interpretar o 
que acontece ao leitor; é um princípio de "estruturação dos processos e das experiências de vida" (RIZZOLI, 2005, p. 11).

A personalidade da mãe porquinho foi a que menos necessitou de intervenção das professoras, pois a espontaneidade trazida pela turma foi suficiente para construí-la, uma vez que havia nela a representação de muitas experiências.

A definição de cada personagem da releitura em construção permitiu que as crianças trouxessem para o enredo situações cotidianas, o que revela o potencial da literatura infantil para o resgate de vivências das crianças. Para Azevedo (2007, p. 7), a construção de narrativas "é um procedimento que, sem dúvida, ajuda a estruturar e tornar compreensível a experiência de vida, não de forma solitária, mas sim, note-se, por meio da sociabilidade e do contato dialógico com o outro".

Conceder oportunidades nos espaços educativos para que as crianças surdas relatem suas experiências na Libras é uma estratégia para significar o mundo, e, na perspectiva de Quadros (2000), para desenvolver a consciência sobre a língua.

Com os personagens já definidos, a construção do roteiro passou a ser o foco da turma. Esse processo teve início com uma conversa sobre as dramatizações feitas na universidade, sobre o que leram em sala de aula e sobre os recontos que fizeram. Nessa conversa, cada cena era definida, fazendo-se um registro em vídeo (Libras) e, depois, na forma escrita (Língua Portuguesa). Cada registro permitia às crianças aprenderem sobre ambas as línguas.

Conforme Quadros (2000), no contexto escolar da criança surda, são as possibilidades intensas e diversas para se expressar na Libras que sustentam o conhecimento gramatical dessa língua, e que dará suporte para o processo da escrita, em especial na segunda língua, o português. "As oportunidades que as crianças têm de expressar ideias, pensamentos e hipóteses sobre suas experiências com o mundo são fundamentais para o processo de aquisição da leitura e escrita" (QUADROS, 2000, p. 59).

Nesse sentido, todo o registro da narrativa feita pela turma acontecia em Libras, para que a construção gramatical nessa língua fosse priorizada. Depois de construído e registrado o roteiro em Libras, a cada dia de aula, uma ou duas cenas eram registradas em português escrito, priorizando-se uma 
construção textual que fosse significativa para a turma, e de modo que os alunos refletissem sobre o que estava sendo escrito.

Em seguida, foi confeccionado um livro da história criada pelas crianças. Nesse livro, conforme os registros escritos no português eram interpretados em Libras pela professora, as conversas indicavam como ele seria ilustrado. Os personagens eram feitos de dobraduras, as casinhas, de palitos de sorvetes, e ainda havia recortes coloridos e desenhos feitos pelas próprias crianças.

O enredo criado pelos alunos trouxe os quatro filhos porquinhos, cada um caracterizado por vestimentas com estampas em uma forma geométrica. Os porquinhos moravam com sua mãe e mais uma irmã, que era bebê. Por serem muito bagunceiros, a mamãe porquinho ficou muito estressada, e decidiu que era hora de seus filhos começarem a ser independentes, e, para isso, deveriam construir suas próprias casas.

O processo de construção das casas refletia a personalidade de cada porquinho, além da forma geométrica de cada um. O porquinho com forma de triângulo construiu uma casa, usando papel como material, por ser mais rápido. $O$ porquinho com forma de círculo só se preocupou em enfeitar sua casa, sem pensar na resistência. O porquinho com forma de retângulo não terminou a construção da casa, pois trabalhava de pouquinho em pouquinho. Já o porquinho com forma de quadrado fez sua casa pensando na segurança, se dedicando de forma responsável numa construção correta.

O lobo iniciava sua participação na história com sua filha, que o avisava que estava com fome. Assim, ele foi à floresta para procurar comida e se deparou com os porquinhos. Baseando-se na história tradicional, no enredo construído pelas crianças, o lobo, no caminho para a casa dos porquinhos, ameaçava um de cada vez, e, não tendo sucesso na captura, destruía a casa, uma a uma, com um forte assopro, fazendo com que cada porquinho fugisse para a casa do irmão. O lobo, porém, não teve sucesso em sua estratégia ao tentar destruir a casa do último porquinho; assim, decidiu invadir a casa pela chaminé, a fim de garantir uma farta refeição.

As cenas tomavam um contorno próprio em cada fala das crianças todas pensadas por elas -, ao encenarem os porquinhos provocando o lobo, nas expressões faciais que faziam durante as cenas, na maneira que interpretavam os momentos de fuga trazendo humor para as cenas e nas estratégias do lobo para ter êxito em seu plano. 
Em todas as vezes que encenavam, a espontaneidade marcava forte presença, abria-se espaço para novas fantasias, para que novos detalhes fossem descobertos. As contribuições desse processo seguiam uma via de mão dupla: as crianças enriqueciam a história e se enriqueciam com todas as fantasias que a história deflagrava (RIZZOLI, 2005). Por esse motivo, os ensaios nunca eram iguais, assim como as apresentações na escola e no evento do município, que contaram com momentos de espontaneidade.

Partindo dessa espontaneidade e do humor que as crianças trouxeram, o desfecho da história contou com a criatividade delas. Em vez de se ter o final convencional em que o lobo é queimado ao entrar pela chaminé, na versão da turma o lobo foi afugentado pela furiosa mãe porquinho, que espantou o lobo com um tamanco na mão, deixando bem claro que não permitiria que ele fizesse mal aos seus filhos.

Além de o enredo original sofrer mudanças criativas por parte das crianças, aspectos culturais provenientes da cultura surda também foram inseridos. Como todos os personagens eram surdos, marcações visuais os orientavam durante a peça. O lobo, quando diante da porta da casa dos três porquinhos, acionava uma campainha visual, que fazia uma luz acender. A mamãe porquinho, para chamar a atenção do lobo, tocou em seu braço enquanto ele se preparava para subir a escada e entrar na chaminé. A mamãe, para repreender seus filhos no momento da bagunça, batia forte os pés no chão para que eles sentissem a vibração. Esses são alguns exemplos de marcadores que ilustram como o enredo fora construído, considerando representações próprias do "ser surdo" (LOPES; VEIGA-NETO, 2010) e, dentre elas, a experiência do olhar direcionando cada momento da peça.

Analisando o processo de construção de releitura da história, chamamos a atenção para o fato de que todas as etapas que originaram uma apresentação teatral consideraram o protagonismo das crianças surdas. A visita das crianças à universidade proporcionou o acesso a releituras, de um clássico da literatura infantil, por meio da Libras, e que, em detalhes, puderam considerar representações da cultura surda. Tal trabalho pode ser continuado na escola e revelou que as crianças se beneficiaram de práticas educativas mediadas pela literatura infantil.

Da visita à universidade ao trabalho na escola, as crianças conseguiram se colocar em uma postura de empoderamento, pois tiveram a possibilidade de ampliar seu repertório cultural, linguístico e social, tão restrito 
devido às circunstâncias sociais, geralmente marcadas pela limitação de oportunidades de práticas discursivas na língua de sinais.

\section{Considerações finais}

Neste capítulo, foram apresentadas reflexões sobre as contribuições da literatura, como prática cultural e interdisciplinar no trabalho com crianças surdas, que oportunizam experiências de ampliação da leitura de mundo e da percepção de si mesmo nas relações cotidianas e no desenvolvimento de competências linguísticas.

As práticas educativas originadas do acesso a releituras de um clássico infantil centraram-se na compreensão, estruturação e criação de histórias, e contribuíram para a produção de narrativas em Libras, que é um importante passo também para a construção textual em língua portuguesa. Se os conhecimentos da língua escrita se constroem numa base de comparação com a primeira língua da criança surda, temos aí mais uma contribuição das práticas de (re)conto e das criações de narrativas, feitas inicialmente em Libras, e, depois, na língua escrita, ou seja, em português.

As experiências oportunizadas pelo trabalho aqui relatado, envolvendo a literatura infantil e a articulação entre escola e universidade, proporcionaram vivências pedagógicas bilíngues e interculturais para todos os envolvidos.

Dentre os frutos desse trabalho, da parte das crianças surdas, aqui constantemente enfatizadas, destacamos seu envolvimento ativo nas vivências de recontos das histórias dramatizadas a partir da visita à universidade, o que possibilitou um trabalho interdisciplinar em sala de aula e que resultou em uma apresentação teatral, o que foi possível devido às práticas de recontos das literaturas apresentadas que proporcionaram, além do desenvolvimento linguístico, o protagonismo da criança surda no processo de construção do seu conhecimento.

\section{Referências}

ABRAMOVICH, Fanny. Literatura infantil: Gostosuras e bobices. São Paulo:

Scipione, 1991. 
ANDREIS-WITKOSKI, Silvia; FILIETAZ, Marta Rejane Proença. A interface entre a apropriação da linguagem por sujeitos surdos e a língua de sinais. Revista Sinalizar, Goiânia, v. 4, 2019.

AZEVEDO, Ricardo. Conto popular, literatura e formação de leitores. 2007. p. 1-07. Disponível em:

http://www.ricardoazevedo.com.br/wp/wp-content/uploads/Contospopulares.pdf. Acesso em: 28 jun. 2020.

COELHO, Betty. Contar histórias: a arte sem idade. São Paulo: Ática, 1993.

DELMAR, Alessandra Scarpin. Conto e reconto de histórias na educação infantil: o uso de estratégias visuais no letramento de crianças surdas. Revista Espaço. Rio de Janeiro, n. 45, jan./jun 2016.

GOES, Maria Cecília Rafael. Linguagem, surdez e educação. São Paulo: Autores Associados, 2002.

GURGEL, Taís Margutti do Amaral et al. Aquisição de Libras na Educação Infantil: um trabalho a partir de narrativas. In: LACERDA, Cristina Broglia Feitosa de; SANTOS, Lara Ferreira dos; MARTINS, Vanessa Regina de Oliveira. Escola e diferença: caminho para educação bilíngue de surdos. São Carlos: Edufscar, 2016. p. 65-78.

KETTEMAN, Helen. Os três jacarezinhos. São Paulo: Autêntica, 2010.

LEBEDEFF, Tatiana B. et al. Quem conta um conto aumenta vários pontos: uma discussão sobre a importância e a arte do contar histórias para o desenvolvimento de crianças surdas. Ponto de Vista, Florianópolis, n. 6/7, p. 97-105, 2004/2005.

LODI, Ana Claudia Balieiro; LUCIANO, Rosana de Toledo. Desenvolvimento da linguagem de crianças surdas na língua brasileira de sinais. In: LODI, Ana Claudia Balieiro; LACERDA, Cristina B. F. (org.) Uma escola, duas línguas, letramento em língua portuguesa e língua de sinais nas etapas iniciais. Porto Alegre: Mediação, 2014. p. 33-50. 
LOPES, Maura Corcini; VEIGA-NETO, Alfredo. Marcadores culturais surdos. In: VIEIRA-MACHADO, Lucyenne Matos da Costa; LOPES, Maura Corcini (org.) Educação de surdos: políticas, língua de sinais, comunidade e cultura surda. Santa Cruz do Sul: Edunisc, 2010. p. 116-137.

QUADROS, Ronice Muller. Alfabetização e o ensino da língua de sinais.

Textura, Canoas, n. 3, p. 53-62, 2000.

REILY, Lucia. Escola inclusiva, linguagem e mediação. Campinas: Papirus, 2012.

RIZZOLI, Maria Cristina. Leitura com letras e sem letras na educação infantil do norte da Itália. IN: FARIA, Ana Lúcia Goulart e MELLO, Suely Amaral (orgs.). Linguagens infantis: outras formas de leitura. Campinas: Autores Associados, 2005, p. 5-22.

SANTANA, Ana Paula; BERGAMO, Alexandre. cultura e identidades surdas: entrecruzilhada de lutas sociais e teóricas. Educ. Soc., Campinas, v. 26, n. 91, p. 565-582, maio/ago. 2005.

SANTIAGO, Vania de Aquino Albres; ANDRADE, Cristiane Esteves. Surdez e sociedade: Questões sobre conforto linguístico e participação social. Libras em Estudo: Política Linguística, São Paulo: Feneis, p. 145-163, 2013.

SCIESZKA, John. A verdadeira história dos três porquinhos. São Paulo: Cia das Letrinhas, 1993.

SOUZA, José Marcos Rosendo de, COSTA, Maria da Conceição, SAMPAIO, Maria Lucia Pessoa. Surdez, reconto e formação leitora. Cadernos de Letras da UFF, v. 26, n. 52, p. 547-563, 2016.

TARTUCl, Dulcéria. A Educação Bilíngue e o acesso à Língua Brasileira de Sinais na Educação Infantil. Revista Espaço 44, Rio de Janeiro: INES, 2015, jul/dez, p. 47-66. 
TORERO, José Roberto; PIMENTA, Marcus Aurelius. Os 33 porquinhos. Cia das Letrinhas: São Paulo, 2017.

TRIVIZAS, Eugene. Os três lobinhos e o porco mau. São Paulo: Brinque-book, 1996.

VIEIRA, Alice. Formação de Leitores de Literatura na Escola Brasileira:

Caminhadas e labirintos. Cadernos de pesquisa, v. 38, n. 134, p. 441-458, maio/ago. 2008.

VILLELA, Bia. Os três porquinhos. São Paulo: Paulinas, 2006.

VYGOTSKY, Lev Semenovitch. A formação social da mente: o desenvolvimento dos processos psicológicos superiores. 7. ed. São Paulo: Martins Fontes, 2007.

VYGOTSKY, Lev Semenovitch. Pensamento e linguagem. Trad. Jefferson Luiz Camargo, 4. ed. São Paulo: Martins Fontes, 2008. 